\title{
ATUAÇÃO BIBLIOTECONÔMICA NO E-COMMERCE
}

\section{PERFORMANCE OF LIBRARIANSHIP IN E-COMMERCE}

\author{
Allan David Nunes da Silvaa \\ Jaqueline Santos Barradas ${ }^{b}$
}

\begin{abstract}
RESUMO
Introdução: Expõe o crescimento e a popularização da internet e do E-commerce no Brasil e consequentemente a abertura de novas vagas e emprego para os profissionais da informação. Objetivo: Analisa a prática biblioteconômica e a participação de bibliotecários em uma empresa de E-commerce. Metodologia: Apresenta um estudo de caso de empresa de E-commerce e discute as respostas da aplicação de um questionário Resultados: Declara que a atuação do bibliotecário no E-commerce contribui para a visibilidade da profissão e que há lugar para a prática biblioteconômica em mercados não tradicionais de informação bem como a sua colocação no mercado de trabalho formal. Conclusões: Conclui que o bibliotecário possui as competências para atuar no E-commerce. Sugere a atualização das matrizes curriculares para o atendimento das demandas biblioteconômicas no comércio eletrônico digital.
\end{abstract}

Descritores: Biblioteconomia. Bibliotecários. E-commerce. Atuação profissional.

\section{INTRODUÇÃO}

A Biblioteconomia é entendida no senso comum como um curso que prepara profissionais para atuarem exclusivamente em bibliotecas e centros de pesquisas tradicionais. Contudo, a Classificação Brasileira de Ocupações (CBO) em seu código de registro de no 2612 descreve o bibliotecário como profissional da informação que pode atuar em áreas para: disponibilizar informações em diferentes suportes; gerenciar unidades de informação, redes e sistemas de informação; tratar tecnicamente e desenvolver recursos informacionais; disseminar informação; desenvolver estudos e pesquisas; prestar serviços de assessoria e consultoria;

\footnotetext{
a Bacharel em Biblioteconomia pela Universidade Federal do Estado do Rio de Janeiro. E-mail: allandavidns@gmail.com

b Professora Adjunta da Escola de Biblioteconomia da Universidade Federal do Estado do Rio de Janeiro. E-mail: jaqueline.barradas@unirio.br
} 
realizar difusão cultural e desenvolver ações educativas (CBO, 2017).

Para o Conselho Regional de Biblioteconomia da $7^{\underline{a}}$ Região (CRB-7) 0 bibliotecário é o profissional que desenvolve atividades de organização, tratamento, análise e recuperação de informações de forma manual ou automatizada, com o objetivo de atender as necessidades informacionais de usuários e segmentos da sociedade:

O profissional de Biblioteconomia, que tradicionalmente atua em bibliotecas, encontra novas frentes de trabalho em sistemas e redes de informação de setores públicos, empresariais e industriais, escritórios de assessoria e consultoria, organização de arquivos e de documentação particulares, ensino e pesquisa, podendo atuar como analista da informação, como gestor de serviços de informação e também na área de normalização (CRB-7, 2018).

A motivação para essa pesquisa decorreu da experiência de estágio realizado por um dos autores em uma empresa de grande porte, com atuação relevante no E-commerce brasileiro, em que os conceitos aprendidos no curso de Biblioteconomia encontram na prática a possibilidade de empregabilidade dos seus bacharéis em organizações não tradicionais da profissão.

A partir de uma análise da literatura e buscando compreender a atuação profissional em organizações, foi possível chegar ao seguinte questionamento: há espaço para a atuação profissional dos bacharéis de Biblioteconomia nas organizações informacionais não tradicionais, como no E-commerce? Para responder à pergunta 0 presente artigo tem como objetivo analisar a prática biblioteconômica e a participação de bibliotecários em uma empresa de E-commerce.

A atuação do bibliotecário, profissional academicamente preparado para selecionar, tratar, recuperar e disseminar informações, está cada vez menos limitada às bibliotecas tradicionais. As novas práticas da era digital requerem a competência de profissionais da informação para 0 uso dos recursos informacionais que apoiam a tomada de decisão em estratégias de experiência de compra e venda através da Internet. O monitoramento informacional, a captação, o armazenamento, o desenvolvimento, a disponibilização, a indexação, a padronização, a classificação, o estudo de usuário, a técnica de otimizar a estrutura e o conteúdo de um site para assim aumentar a quantidade e qualidade do seu tráfego orgânico, posicionando suas páginas nos primeiros lugares dos 
resultados de pesquisas nos mecanismos de busca que são geridas e operacionalizadas por profissionais da informação são práticas biblioteconômicas.

Em seu artigo, Rebelo (2019) chama a atenção para o bibliotecário, profissão que estava fora dos "holofotes", mas que diante do avanço das tecnologias dentro das empresas, ganha mais espaços de trabalho, conquistando importantes cargos na carreira digital como o User Experience $\left(U X^{1}\right)$ e o combate às fakenews ${ }^{2}$. No artigo a autora reforça a tecnicidade e a curadoria do bibliotecário que tem na profissão o foco no conteúdo informacional e no usuário da informação.

A profissão evoluiu com a sociedade. Se antes a informação só estava registrada nos livros e documentos físicos, hoje ela está registrada, por exemplo, no ambiente digital. A lógica é a mesma, só mudaram os instrumentos de trabalho (REBELO, 2019, n.p).

Além dessa introdução, este artigo está organizado da seguinte forma: na segunda seção apresentam-se os procedimentos metodológicos adotados para a realização da presente pesquisa, descrevendo as técnicas de coleta e as análises dos resultados obtidos. Em seguida aborda-se o histórico do comércio eletrônico no Brasil, o crescimento da Internet e consequentemente as mudanças no comportamento e nas práticas comerciais resultantes da sua popularização. $\mathrm{Na}$ quarta seção abordamos o bibliotecário, profissional da informação capacitado para atuar na área. Na quinta seção apresentaremos uma empresa de e-commerce e suas atividades, ressaltando as áreas que possuem atuação do bacharel em Biblioteconomia. Na penúltima seção são discutidos os resultados da pesquisa à vista do referencial teórico apresentado, finalizando com as considerações finais.

\section{PROCEDIMENTOS METODOLÓGICOS}

O caminho percorrido para operacionalizar essa pesquisa iniciou-se com

\footnotetext{
${ }^{1}$ UX é a sigla para User Experience, Experiência do Usuário em tradução livre, que consiste no conjunto de interações de um usuário, em que o resultado gera uma experiência positiva ou negativa com um sistema, página web, produto ou serviço.

${ }^{2}$ Notícia falsa que consiste na distribuição deliberada de desinformação ou boatos que podem ser disseminados nas mídias sociais.
} 
a revisão da literatura em bases de dados de referência no Brasil, em especial o Scientific Electronic Library Online (SCIELO), filtrando as publicações do Brasil, em língua portuguesa, relacionado com a temática da Biblioteconomia e Ciência da Informação onde foram encontrados: 96 publicações com o termo "Biblioteconomia" e 37 artigos com o termo "E-commerce". A partir desse resultado buscou-se selecionar através da leitura dos resumos, as publicações que tratavam de Biblioteconomia, Biblioteconomia Digital, competências, mercado de trabalho, inteligência competitiva e unidades informacionais, em que foram selecionados um total de 13 publicações.

Para descrever as atividades na empresa de E-commerce, aplicou-se o estudo de caso na organização, nos setores que fossem compostos por pelo menos um bacharel em Biblioteconomia, formado ou em formação. Para conceituar esses setores, buscou-se apoio na literatura e em portais de referência para o E-commerce, como o portal "E-commerce Brasil" e a Associação Brasileira de Comércio Eletrônico.

Foi realizada uma pesquisa exploratória com os bacharéis de Biblioteconomia e os discentes em formação, atuantes nos centros de tecnologia e serviços digitais da maior empresa de E-commerce da América Latina, na cidade do Rio de Janeiro (RJ). Tal pesquisa ocorreu por meio da aplicação de um questionário eletrônico que teve como objetivo mapear os setores selecionados e suas práticas biblioteconômicas, através de perguntas abertas e fechadas de modo que os dados coletados possam ser avaliados à luz do que a literatura discorre sobre o tema.

Nesse sentido fez-se uma pesquisa quali-quantitativa. Qualitativa porque se objetivou compreender os fenômenos através da coleta de dados narrativos, estudando as particularidades e as experiências dos indivíduos. Quantitativa já que o objetivo foi também compreender os fenômenos através da coleta de dados numéricos, apontando preferências, comportamentos (GUNTHER, 2006).

O campo empírico da pesquisa refere-se às seis áreas identificadas na organização com pelo menos um profissional de Biblioteconomia. O questionário foi respondido por 20 profissionais das seis áreas pesquisadas. Cabe ressaltar que os participantes responderam ao questionário voluntariamente após a 
apresentação da proposta e do trabalho, assinando eletronicamente o termo de consentimento livre e esclarecido, através da ferramenta Google Forms.

\section{A INTERNET E O E-COMMERCE NO BRASIL}

De acordo com Chaim (2007, p. 76), "convencional ou eletrônico", o comércio procura atender as seguintes exigências: apreciação da mercadoria, negociação, pagamento e o recebimento do bem ou serviço. Estar bem informado é, além de um desafio, um diferencial para a tomada de decisão nas relações comerciais via Internet, tanto para os vendedores que escolherão onde e como anunciar, quanto para os compradores que decidirão onde e quando comprar.

O acesso à Internet no Brasil atingiu em 2017 a marca de $74,9 \%$ de usuários, o que significa que em cada quatro domicílios, três possuem acesso à Internet. De 2016 para 2017, o percentual de pessoas que acessaram a Internet através do celular aumentou de 94,6\% para 97,0\% (IBGE, 2018). A Figura 1 a seguir apresenta a evolução entre 2016 e 2017:

Figura 1 - Percentual de acesso à Internet por faixa etária entre 2016-2017

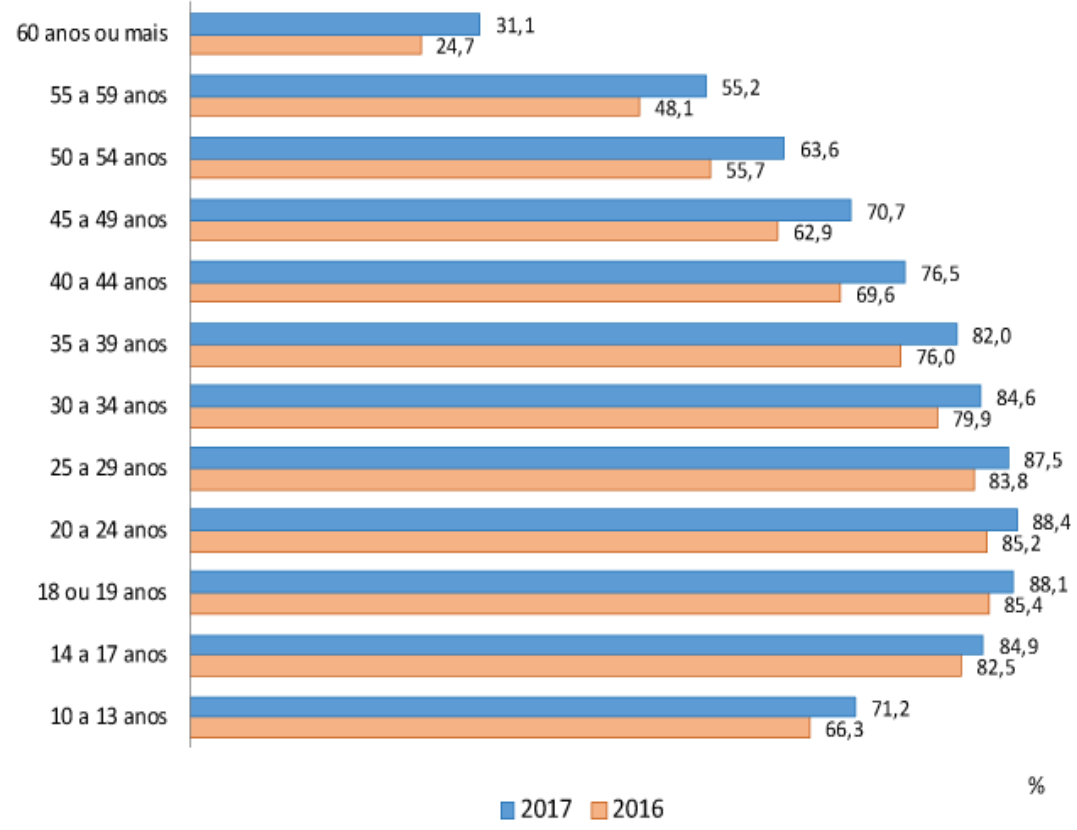

Fonte: IBGE (2018).

O aumento da utilização da Internet é crescente de um ano para o outro 
em todas as faixas de idade, alcançando tanto o pré-adolescente quanto os idosos. Segundo o Sebrae (2007), o crescimento do E-commerce no Brasil está relacionado ao aumento de usuários com acesso à Internet, da percepção do consumidor em não diferenciar o mundo online (E-commerce, lojas virtuais) do mundo off-line (lojas físicas), o que se denomina Omnichannel.

De acordo com o Sebrae (2007), os canais de vendas utilizados por empresas estão cada vez mais convergentes. Criar essa percepção (Omnichannel) para o consumidor e colocá-lo no centro das atenções, melhora a experiência com a marca proporcionando a mesma um destaque na memória do consumidor. Nesse contexto o Sebrae (2007) afirma que "o Omnichannel ainda permite à empresa a conhecer o comportamento e as preferências dos clientes", o que está diretamente relacionado com a inteligência competitiva através do estudo de usuário.

Inteligência competitiva é "o processo de obtenção, análise, interpretação e difusão de informação de valor estratégico sobre a indústria e os competidores, que se transmite aos responsáveis pela tomada de decisões em momento oportuno" (LUCAS; CAFÉ; VIEIRA, 2016, p. 173).

[...] tendo em vista a forte competição entre empresas, instituições e nações [...], a inteligência competitiva (IC) apresenta-se como opção metodológica e prática para o aproveitamento de oportunidades e neutralização de ameaças advindas do contexto competitivo, mediante coleta e análise de informações focando o apoio à tomada de decisão (AMARAL et al., 2008, p. 7).

Segundo Chaim (2007, p. 76), "A inteligência competitiva encontra um campo fértil para identificação das informações estratégicas para penetração e posicionamento no mercado ou obtenção de diferencial competitivo". O serviço de Inteligência Competitiva na observação da concorrência e de como o usuário se comporta na rede, facilitou a expansão do negócio e a parceria multiprofissional para a diversificação das atividades, contribuindo diretamente para a tomada de decisão (CHAIM, 2007).

Assim, a evolução tecnológica mudou o comportamento do consumidor na hora de fazer pesquisas e compras. Novas práticas comerciais foram desenvolvidas para atender as demandas de uma sociedade cada vez mais conectada. As vendas por meio da Internet (E-commerce) tiveram um aumento 
de $290,4 \%$ entre os anos de 2007 a 2014 e mesmo diante dos desafios econômicos e da inflação, esse mercado está em franca expansão e crescimento (IBGE, 2016a). O E-commerce no Brasil cresceu 11\% em 2016, segundo a Associação Brasileira de Comércio Eletrônico (2016), "e obteve um faturamento de $\mathrm{R} \$ 53.491$ bilhões. O ano fechou com 179 milhões de pedidos", o que mostra que mesmo diante de um cenário de crise o E-commerce mantém uma vocação de crescimento.

O crescimento desse comércio no Brasil é impulsionado pelo maior aproveitamento e utilização da Internet, da popularização do smartphones, da confiança e do aumento no hábito de comprar online, pelo crescimento da banda larga, pela alta penetração dos serviços de Internet banking e pelos sortimentos ${ }^{3}$ disponíveis nos sites (IBGE, 2016b).

A velocidade com que o volume de informações "inundam" nossa sociedade, cada vez mais conectada, necessitam de ações proativas para organizar e dispor esse volume de informação no sentido de apoiar as decisões estratégicas na área em que se atua. Diante dessa nova realidade, os profissionais da informação desempenham um papel relevante para as ações estratégicas que serão traçadas para o acolhimento de um público cada vez mais conectado, exigente e "inundado" de informação.

De acordo com Miranda (2004), os domínios de competências informacionais fizeram diferença na efetividade das atividades efetuadas por profissionais que foram preparados para o trabalho com a informação, permitindo melhor desempenho para esses profissionais com base nas competências próprias dos profissionais de informação.

\section{BIBLIOTECÁRIO, O PROFISSIONAL DA INFORMAÇÃO}

A informação como ferramenta estratégica para a tomada de decisão é um desafio para os profissionais que atuam no comércio eletrônico e vem ao encontro da competência do bibliotecário que em sua graduação dispõe de

\footnotetext{
${ }^{3}$ Sortimentos são todos os produtos comercializados por uma loja ou fabricante (TOLEDO, 2015).
} 
disciplinas que o capacitam como profissional da informação para o entendimento das demandas do usuário. Como parte do processo de formação de nível superior, o discente de Biblioteconomia cumpre o estágio supervisionado.

\begin{abstract}
Entende-se como estágio curricular, o procedimento pelo qual o estudante vivencia situações reais de vida e de trabalho, atuando em sua área específica junto à instituição de direito público e privado ou na comunidade em geral. Além de fazer integrar os componentes curriculares do curso de bacharelado em Biblioteconomia, os estágios com 60h (30. Período), 60h (5o. Período), 90h (7o. ou 80.Período), e 90h (80. ou 9o.Período), proporcionam oportunidades de treinamento ao longo do curso integrando teoria e prática (UNIVERSIDADE FEDERAL DO ESTADO DO RIO DE JANEIRO, 2010)
\end{abstract}

Em sua obra Introdução à Biblioteconomia, Fonseca (2010) afirma que a formação do bibliotecário sempre esteve polarizada entre a erudição e a técnica, mas que até os americanos tecnicistas, por iniciativa da American Library Association promovendo estudos e debates sobre a matéria, souberam harmonizar as duas orientações e afirma ainda que "todos os campos do saber [...] exigem [...] disponibilidade para a formação permanente. Ou nos atualizamos ou seremos devorados, como procedia a esfinge com os que não decifravam seu enigma" (FONSECA, 2010, p. 99).

Para Santos et al (2016, p. 19) o profissional da informação tem o papel de "processador" e "filtrador" da informação, buscando melhorar a qualidade para as demandas por pesquisa apresentadas pelos "usuários/clientes". Para Carvalho Silva (2013), no curso de Biblioteconomia há um conjunto de práticas que qualifica a profissão tais como: desenvolvimento de coleções (seleção dos materiais); classificação; catalogação; referência; pesquisa em sistemas de recuperação da informação; administração (planejamento estratégico, estudo do usuário, educação do usuário etc.).
A Biblioteconomia pode ser compreendida como uma disciplina profissional em constante processo de aprimoramento técnico- normativo, pois sua história mostra sua construção e crescimento em termos de atividades organizacionais, de recursos e serviços de informação e do acesso e uso da informação, visando à satisfação das necessidades dos usuários (CARVALHO SILVA, 2013, p. 15).

A organização do conhecimento pressupõe formas de representação. 
Uma das formas de representação da informação é o esquema facetado que tem a capacidade de expressar relacionamentos. Classificações facetadas são aquelas que identificam as características comuns a diversas categorias de um assunto, organizando-se em facetas, que são características próprias de algo ou de alguém, na qual os assuntos são decompostos visando uma síntese. As classificações facetadas estão se tornando cada vez mais presentes na Web, principalmente em sites comerciais (PONTES; LIMA, 2012).

O bibliotecário, assim como todo profissional da informação, necessita capacitar-se constantemente. Segundo Santos (2016) há estudos demonstrando que a capacitação acadêmica, isoladamente, não garante a inserção profissional, embora seja imprescindível para melhorar as condições de empregabilidade.

O surgimento de tecnologias de informações ampliou o campo de atuação dos bibliotecários, mas também trouxe novos desafios. É importante preparar-se para aplicar conhecimentos técnicos em outros cenários informacionais que não sejam apenas em bibliotecas. Neste contexto a empregabilidade dos indivíduos passa a ser amplamente discutida.

Segundo Valentim (2000) o mercado de trabalho do bibliotecário está dividido em: informacional tradicional (bibliotecas públicas, universitárias, escolares, especializadas, centros culturais e arquivos), informacional de tendências (centros de informação/documentação em empresas privadas, bancos e bases de dados eletrônicos e digitais, portais de conteúdo e portais na Internet ou intranet) e informacional existente e não-ocupado (editoras, empresas privadas, provedores de Internet, livrarias, bancos e bases de dados).

O avanço tecnológico desperta na sociedade novas formas de interação social, novos costumes e novas práticas. Em um mundo cada vez mais conectado, a experiência comercial depara-se com novos desafios, que consiste em fidelizar o seu usuário e manter-se atento e informado mediante as tendências e comportamentos de mercado, para dessa forma permanecer competitivo e relevante (FERREIRA, 2018).

A tendência não é exclusiva do profissional de Biblioteconomia, contudo é este o profissional que desde o início de sua formação recebe o preparo 
especializado para compreender as necessidades dos usuários, o monitoramento de informações e a disseminação da informação (entre outras competências). Sobre esse papel, Valentim (2002, p. 36) declara que "a globalização e as tecnologias da informação disponíveis hoje quebram a ideia de um acervo restrito a quatro paredes, mas, mesmo assim, não diminuem a responsabilidade do bibliotecário na relação, fontes e necessidade de informação".

Segundo Borges (2004), a vinda do bibliotecário para novos mercados de oportunidade, como o E-commerce, por exemplo, tende a ser cada vez mais produtiva e necessária, pois esse profissional é um exímio conhecedor, organizador e disseminador de informação, dedicado a atender às demandas de seus usuários. Em parceria com as demais áreas do conhecimento, empresas, clientes e fornecedores tendem a explorar o universo digital, mapeando comportamentos e valorizando seus produtos e serviços.

De acordo com Ferreira (2018), no comércio eletrônico, as companhias procuram fidelizar seus clientes através dos acessos às suas páginas na web de forma que com poucos cliques o consumidor possa encontrar o produto que deseja ou ser direcionado para um item em potencial convergindo para a compra.

As ofertas de sites de comércio são inúmeras e diante disso as empresas procuram estudar quais dentre as tantas páginas de produtos e serviços, são os seus concorrentes diretos, ou seja, quais empresas que vendem o mesmo sortimento, com as mesmas condições, além de atender às exigências das agências regulatórias no país, informações estas que precisam ser monitoradas (FERREIRA, 2018).

Estabelecido o ramo de atuação as empresa dispõem de equipes multi e interdisciplinares no atendimento das demandas do negócio, tais como auxiliares, técnicos, analistas, gestores etc. Nesse passo, uma equipe de profissionais, ficará com a atribuição de monitorar a concorrência, acompanhar as variações, ofertas, promoções e estratégias comuns ao mercado online e observar e estudar as necessidades e o comportamento que direcionam as ações de seu cliente, transformando dificuldades em soluções e oportunidades de negócio. Sobre isso, Madureira e Vilarinho (2010, p. 90) afirmam que "se 
antes a atividade do bibliotecário podia ficar restrita aos limites físicos de uma biblioteca e de uma coleção, agora o uso difundido da tecnologia a serviço da informação transpõe barreiras físicas e institucionais".

Uma equipe trabalhará a captação, o armazenamento, a análise da informação, o monitoramento, o estudo e a experiência do usuário, e a disseminação das informações relevantes para o seu negócio, que de posse desse conhecimento definirá suas estratégias e tomadas de decisões.

\section{A EMPRESA DE E-COMMERCE E SUAS ATIVIDADES}

A organização objeto deste estudo é uma empresa comercial que dispõe de um centro de tecnologia localizado na cidade do Rio de Janeiro (RJ). Possui um conjunto de setores multiprofissionais e multidisciplinares onde desenvolvem e gerenciam suas ações. Como o foco desta pesquisa é a atuação biblioteconômica, limitaremos nossas descrições para os setores que possuem pelo menos um profissional dedicado, graduando ou graduado em Biblioteconomia. Através do programa de estágio das universidades conveniadas com essa organização, os discentes dos cursos do Rio de Janeiro tiveram a oportunidade de ingressar na companhia e experimentar as mais variadas práticas possíveis para exercerem a profissão bibliotecária. Nesse contexto dezenas de graduandos ingressaram na corporação sendo grande parte efetivada pela mesma como analista e auxiliar informacional, entre outros cargos (a corporação já possuía dois bibliotecários registrados).

\subsection{OS Setores e a Atuação Biblioteconômica}

A seguir explicaremos o contexto e a prática biblioteconômica dos setores selecionados, onde foi aplicado o questionário para analisar e compreender as atividades. 


\subsubsection{Customer Success \& Intelligence (CSI)}

O CSI, que em tradução livre quer dizer Sucesso do Cliente e Inteligência, fornece informações para promover o sucesso competitivo para o seller ${ }^{4}$ contratante. Esses profissionais monitoram a concorrência e disponibilizam através de um portal, gráficos, estatísticas e dados que apoiam o cliente na tomada de decisão para a variação de preços.

Esse grupo subdivide-se na operacionalização e na gestão das informações entre: monitoramento informacional - que monitora os preços da concorrência; em desenvolvedores de script do bot - robô que faz a captação de dados que alimentará o repositório dos dados que serão trabalhados; no relacionamento com o cliente (Seller) - que recebem do cliente as demandas; e a supervisão - que faz a gestão de pessoas desse grupo.

O subgrupo de monitoramento de dados trabalha a captura manual e também dos dados recolhidos pelo robô, o armazenamento as análises de dados que alimentará o portal que irá disponibilizar as informações para o cliente.

Os desenvolvedores de scripts, também chamados de SETUP (arquitetura, armação e organização do sistema), desenvolvem linhas de comando para a captação dos dados em HTML das páginas de E-commerce, e o desenvolvimento da automação do monitoramento informacional que ainda precisará ser verificado por pessoas.

O grupo de relacionamento com o cliente recebe as informações que o mesmo precisa para desenvolver o seu negócio. A supervisão gerencia o grupo. O CSI entrega para o seu cliente, através de um portal, todas as informações comerciais em torno do item monitorado que gera conhecimento para a tomada de decisão nas ações de vendas nos marketplaces.

\subsubsection{Gestão de Sortimentos}

Essa equipe trabalha com a classificação, padronização, hierarquização e

\footnotetext{
${ }^{4}$ São os vendedores que expõem seus produtos dentro de um marketplace. Essa é a nomenclatura oficial e que é utilizada por alguns dos principais players do mercado (MELMAN, 2016).
} 
gestão estratégica da informação. Esse setor atende vendedores (sellers) que anunciam seus produtos na vitrine do site da empresa. Fazem o tratamento do sortimento, tais como: a junção de anúncios no site (pode ser por demanda do seller junto ao departamento comercial) ou trabalhando na estruturação da vitrine de setores do site através das Verticais (móvel, beleza etc.) que também dispõe de uma equipe de suporte, recebendo um chamado (pedido) e tentando solucionar um problema ou sanar alguma dúvida. Enquanto o time anterior monitora e desenvolve serviços da concorrência para a concorrência, este setor trabalha o sortimento dos sites da própria organização.

\subsubsection{Search Engine Optimization (SEO)}

SEO é a sigla para Search Engine Optimization, ou Otimização de Mecanismo de Busca, em tradução livre, quanto melhor as estratégias adotadas, mais chances de um site aparecer na primeira página de resposta das pesquisas do Google.

Com o aumento da economia online no Brasil, compras pela Internet são iniciadas através de mecanismos de buscas, como o Google, por exemplo, o dispositivo de pesquisa mais usado do mundo, segundo dados do portal Statcounter (apud CUNHA, 2019). Esse grupo monitora conceitos e termos que serão mais bem indexados nas páginas de E-commerce da organização, com o objetivo de ser rastreado (lido) pelo bot do Google no melhor tempo, e permanecer relevante na primeira página de resultados indexados por este buscador. A figura 2 exemplifica as ações desse time:

Figura 2 - Pilares do SEO
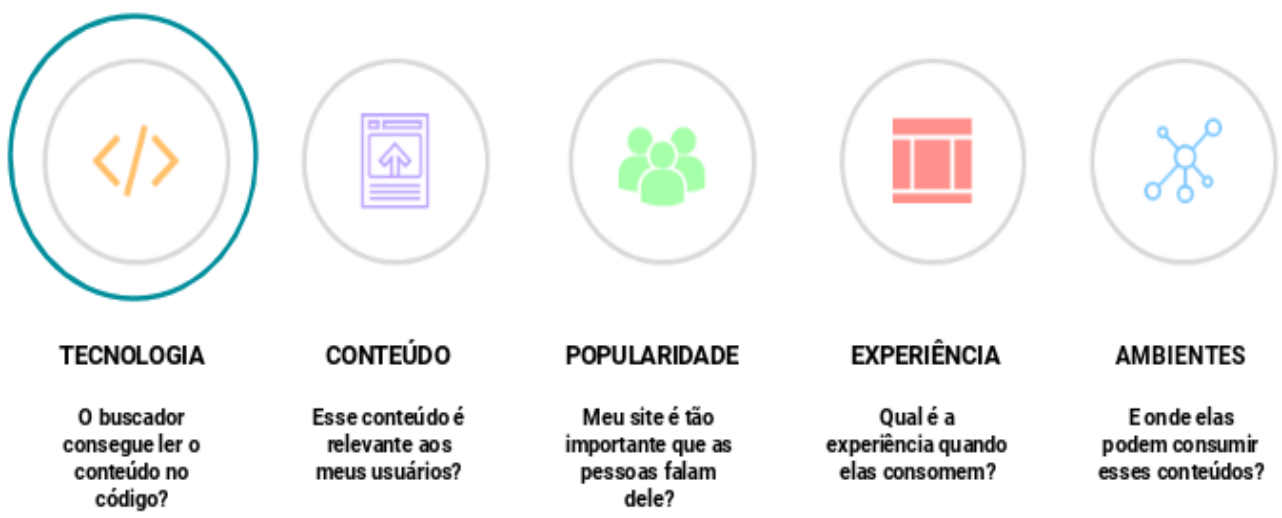

CONTEÚDO

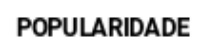

EXPERIÊNCIA

AMBIENTES

Esse conteúdoé relevante aos

Meu site é tão importante que as pessoas falam

Qualé a experiência quando elas consomem?

Fonte: Cunha (2019). 
O grupo trabalha pelo melhor posicionamento dos sites nos resultados de busca, através da indexação seguindo os parâmetros do Google que analisa (lê) a estrutura do site, o conteúdo, a autoridade, a atualidade das informações, o tempo que o usuário permanece no site, a popularidade e a experiência de uso etc.

O SEO é um pesquisador contínuo para o mapeamento de termos para nomear categorias, para mapear termos que serão incorporados no conteúdo das páginas, fazer a identificação dos termos sazonais, e assim garantir que esses termos estarão de acordo com o "top três do buscador" (Google), além de monitorar os termos não utilizados e os termos mal posicionados (os que aparecem na segunda ou terceira página) evitando que os mesmos sejam utilizados pela organização (CUNHA, 2019).

\subsubsection{User Experience (UX)}

UX significa User Experience, que significa Experiência do Usuário em tradução livre. Essa equipe trabalha no mapeamento das percepções dos usuários, ao navegarem pela página web da corporação, equilibrando aspectos práticos, experienciais, significantes e a interação, na experiência de quem usa sendo um setor bastante multidisciplinar.

Figura 3 - As disciplinas de $U X$

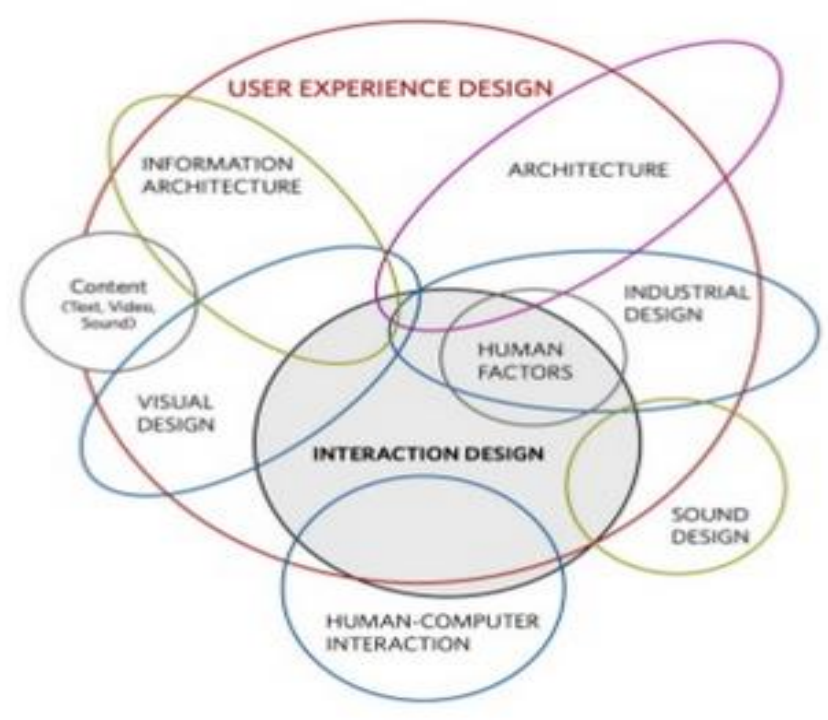

Fonte: Teixeira (2015). 
A contribuição biblioteconômica nesse setor se faz através da arquitetura da informação e a padronização de informações em busca de uma língua em comum. Esse time é responsável por definir como os usuários irão interagir com o site, em que ordem as telas serão apresentadas, organizando o conteúdo dentro do site. Essa equipe precisa ter conhecimento sobre como os usuários consumirão facilmente a informação aumentando a motivação e reduzindo os ruídos e os obstáculos para que estes completem a operação e sigam adiante, o que significa: comprar no site (TEIXEIRA, 2015).

Esse setor estará sempre atento à usabilidade do usuário na grande biblioteca virtual que é a página da empresa, com o objetivo de fazer o usuário completar a operação. É importante criar uma interface simples e amigável, que seja fácil de usar, fazer o usuário permanecer mais tempo no site e fidelizar o mesmo para que ele volte sempre e que a indique seus contatos, amigos etc e para comprarem no site (TEIXEIRA, 2015).

O bibliotecário arquiteto da informação organiza e cataloga os títulos dentro dessa "biblioteca digital", para que esses sejam facilmente encontrados pelo visitante. A atuação biblioteconômica nessa área contribui, além do que já foi expresso até aqui, na ordenação dos itens, no estudo de usuários e na taxonomia que nessa área consiste em rotular uma informação de forma que a mesma faça sentido para o usuário, classificando os itens em esquemas taxonômicos que categorizam a informação (TEIXEIRA, 2015).

Assim, nesse objetivo de facilitar a comunicação, a equipe de $U X$ documenta as decisões tomadas nas reuniões, alinham essas decisões com as estratégias que estão sendo produzidas, analisam seus concorrentes (análise competitiva) entendendo os padrões que estão sendo criados para identificar oportunidades e inovação nos negócios da companhia. Fazem ainda as análises métricas (número de cliques, tempo de navegação, palavras-chave usadas etc.) e produzem bibliotecas de padrões do site (lista com padrões de interação no site) (TEIXEIRA, 2015).

\subsubsection{Integralização}

Esse setor ajuda os sellers (vendedores) a venderem seus produtos nos 
principais marketplaces ${ }^{5}$ do país. Integram e gerenciam todos os pedidos em todos os canais de venda de marketplaces, que são quando os sellers expõem seus produtos em grandes e-commerces (players), que cobram uma comissão sobre as vendas. Os grandes players ampliam e diversificam seu portfólio, e o seller tem maior chance de ser visto, o comprador (consumidor, cliente) passa a ter mais variedade (sortimento) no site de uma marca que já conhece e confia.

De acordo com Caires (2019), esse setor pode ser entendido como um conjunto de valores, conhecimentos, habilidades e atitudes que envolvem a abordagem de conceitos, fatos e princípios como procedimental (saber fazer) e atitudinal (saber ser), com a intenção de ser transmitido para garantir 0 desenvolvimento de algo e/ou alguém. Na área de Conteúdo, tudo que existe na plataforma e tudo que é implementado e atualizado é registrado (Confluence) para a memória da empresa (gestão do conhecimento) e divulgado para o seller (e-mail marketing, Blog e Central de Ajuda) de forma que ele tenha ciência e possa manusear a plataforma com conhecimento e livremente. "Inteligência de conteúdo é a tecnologia que fornece dado e insights para conteúdos próprios com o objetivo de aumentar os resultados" (DRUBSCKY, 2018, n.p). As funções da área de conteúdo consistem em tomar ações inteligentes com base nos dados:

a) Dados internos: são aqueles acessíveis ao controle, ou seja, informações que estão no Google Analytics, métricas do Zendesk (software para o serviço de atendimento ao cliente hospedada na nuvem), no CRM (Salesforce) - Customer Relationship Management em tradução livre: Gestão de Relacionamento com o Cliente é um software que integra dados, informações clientes, histórico e preferência de compras, na plataforma de automação (documentação de TI no "Jira6") e no seu sistema de business intelligence da empresa.

5 Pode ser compreendido como um modelo de negócio onde marcas com alto tráfego disponibilizam espaço para diferentes perfis de lojistas anunciarem seus produtos dentro dos seus sites. (MELMAN, 2016).

${ }^{6}$ Ferramenta que permite o monitoramento de tarefas e acompanhamento de projetos garantindo o gerenciamento de todas as suas atividades em único lugar. 
b) Dados externos: são os coletados através de pesquisas e questionários enviados semestralmente aos usuários (sellers da equipe de integração). Com os dados em mãos são criados e atualizados novos conteúdos para registro interno (gestão do conhecimento da empresa) e divulgação aos sellers. A indexação é realizada de acordo com conceito SEO (otimização de busca), vocabulário controlado (normalização e normatização) e uso de tags (folksonomia) para melhor recuperação dos sellers e colaboradores. (CAIRES, 2019).

\subsubsection{Desenvolvedores (TI)}

Esse setor tem como objetivo garantir a consistência da experiência do cliente com a marca, seja no site ou no aplicativo. Trabalham em conjunto com as outras áreas garantindo o suporte tecnológico (TI) e gerenciando as tarefas e o software de colaboração de equipe, aberto e compartilhado (Confluence) para documentar as demandas no Jira. Jira é um software comercial desenvolvido pela empresa Australiana Atlassian. É uma ferramenta que permite o monitoramento de tarefas e acompanhamento de projetos garantindo 0 gerenciamento de todas as suas atividades em único lugar.

\section{RESULTADOS E ANÁLISE DOS DADOS DA PESQUISA}

O questionário produzido para essa etapa da pesquisa exploratória foi composto por cinco perguntas, cada qual com um objetivo específico, para proporcionar maior familiaridade com o tema, descrevendo a atuação biblioteconômica com a realidade (SILVEIRA; CÓRDOVA, 2009).

Para analisar a prática biblioteconômica na organização, a pesquisa quantitativa reuniu dados que puderam ser transformados em estatísticas utilizáveis. Essas quantificações, opiniões e comportamentos foram generalizados nos resultados a seguir apresentados.

O questionário foi enviado em junho de 2019, para um total de 35 profissionais nos seis setores da empresa e respondidos por 20 , isso representa 
$66 \%$ de profissionais dos seis setores participantes. Os profissionais estão distribuídos nos setores conforme a figura abaixo:

Figura 4 - Áreas de atuação

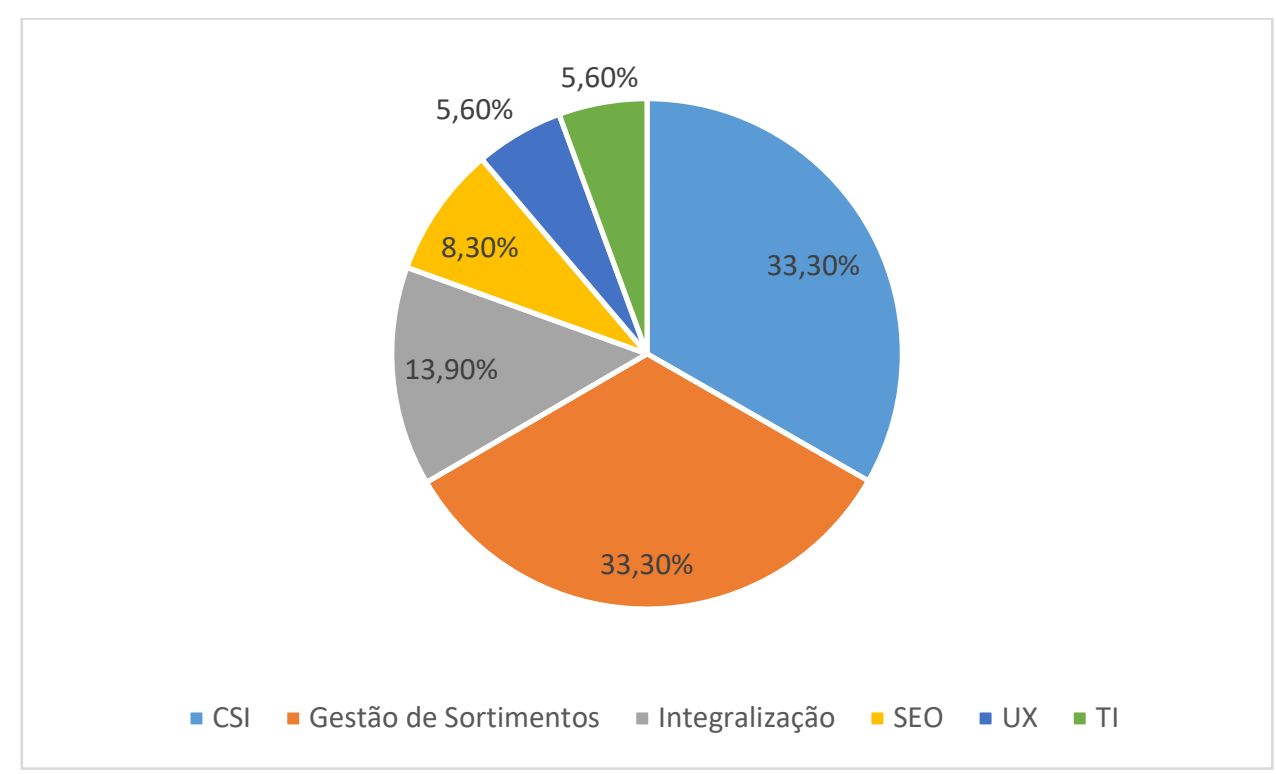

Fonte: Os autores (2019).

No que se refere à pergunta de número 1 , os 20 profissionais declararam ingressar na empresa através da Biblioteconomia, representando um total de $100 \%$ da amostra.

Em relação à pergunta 2, 18 profissionais declararam ingressar na empresa de E-commerce através do programa de estágio de Biblioteconomia, representando $90 \%$ da amostra. Dois profissionais (10\% da amostra) declararam ingressar diretamente através dos processos seletivos divulgados nas redes sociais de negócios, como por exemplo, o Linkedin ${ }^{7}$ (citado na amostra).

Quanto à pergunta 3 , os 20 profissionais declararam suas áreas de atuação, porém os mesmos não relacionaram suas micro áreas com as áreas macro, já que esses setores organizam a divisão do trabalho em subáreas, descritas na seção 5.1 .

Quanto à pergunta 4 (O que você faz?), 20 profissionais descreveram suas atividades de acordo com o cargo que ocupam na empresa, isso representa $100 \%$ da amostra. Ao descreverem o que fazem, os profissionais declaram

\footnotetext{
${ }^{7}$ Linkedin é uma rede social de negócios fundada em dezembro de 2002 e lançada em 5 de maio de 2003 (LINKEDIN, 2019).
} 
atuações compatíveis com a formação biblioteconômica como, por exemplo:

a) ações de visibilidade do "acervo digital" e análises estratégicas dos dados, participação ativa na jornada do cliente, desde o briefing, até o pós-venda;

b) suporte informacional para as equipes que sustentam o site monitoramento de dados, engajamento dos clientes;

c) supervisão de operações; blindagem das equipes das interrupções que estão fora do escopo do trabalho, análise de produtos e junção de anúncios;

d) métricas e gráficos de categorização, taxonomia e estruturação mercadológica;

e) aumento da qualidade do sortimento (coleção de itens) seja na categorização, enriquecimento de cadastro, normalização, machine learning 8 , e o que for necessário para atender à necessidade;

f) estudo de usuários, classificação, referência etc;

g) automatização de processos através de modelagem de dados no CRM Salesforce, criação de dashboards ${ }^{9}$ para gestão da equipe comercial, suporte comercial e operacional;

h) criação e indexação de conteúdos;

i) análise de SEO (cuida do tráfego orgânico do site) buscando melhorias para aumento de vendas de forma orgânica (gratuita);

j) scrummaster do time que significa: responsável por remover obstáculos;

k) coleta de dados; match (casamento, combinação, relacionamento, correspondência) de itens através de buscas em sites para armazená-los na base de dados da empresa, trabalhando esses dados para serem disponibilizados no portal de monitoramento de

8 O aprendizado automático ou aprendizado de máquina é um subcampo da ciência da computação que evoluiu do estudo de reconhecimento de padrões e da teoria do aprendizado computacional em inteligência artificial.

9 Painéis de controle que fornecem visões instantâneas dos principais indicadores de desempenho relevantes para um determinado objetivo ou processo de negócios. 
preços do cliente, manutenção de crawlers e análise competitiva do mercado em relação à marca da empresa, entre outras atividades afins à Biblioteconomia.

Quando perguntados sobre a relação biblioteconômica com aquilo que fazem, na pergunta 5, 17 profissionais, o equivalente a $85 \%$ da amostra, descrevem as ações biblioteconômicas sendo praticadas nas funções. Para a translação dos termos utilizados nas amostras, quando necessário, foi utilizado o Dicionário de Biblioteconomia e Arquivologia, de Cunha e Cavalcanti (2008).

As práticas biblioteconômicas nas seis áreas de E-commerce mais citadas foram: catalogação, com sete menções; técnicas de recuperação e disseminação da informação (TRDI), com seis menções; indexação e categorização, com quatro menções; gestão da informação, análise da informação e classificação, com três menções; gestão de pessoas, estudo de usuário e arquitetura da informação, duas menções.

Representação descritiva, filtragem da informação, análise sistêmica, inteligência competitiva, taxonomia, normalização, produção de conteúdo, folksonomia, registro do conhecimento tácito em explícito, referenciação, comparação e interoperabilização foram práticas biblioteconômicas mencionadas uma vez.

Três profissionais declararam não perceber a relação com a Biblioteconomia, o que representa $15 \%$ das amostras, embora tenham declarado atuar nos serviços de monitoramento informacional de preços do marketplace, na gestão de pessoas e de serviços, na prestação de serviços de apoio/suporte e "blindagem" informacional para as equipes que sustentam o site, e na atuação da gestão Scrum, que é uma metodologia ágil para gestão e planejamento de projetos de software. Percebe-se nessa resposta que há um problema de percepção de atuação biblioteconômica, ainda que de uma pequena parte dessa amostra (três profissionais, ou seja, 15\%), apesar de atuarem como filtros da informação, conceito amplamente aprendido e discutido no curso de Biblioteconomia. 


\section{CONSIDERAÇÕES FINAIS}

O comércio eletrônico mostra-se um mercado promissor e em expansão no Brasil, podendo o bibliotecário atuar nessa prática informacional. O mercado digital é uma área amplamente multi e interdisciplinar, assim como a Biblioteconomia, sendo essa última, uma área cada vez mais conhecida por pesquisadores e profissionais da informação nas organizações além da biblioteca tradicional e centros de pesquisa, apesar de o senso comum e de grande parte das ofertas de emprego na iniciativa privada, o bibliotecário ainda ser entendido apenas como um "curador" de livros da biblioteca (VALENTIM, 2002).

O bibliotecário possui as competências para atuar em diferentes setores das empresas de comércio digital, tanto na parte operacional e de gestão quanto no fornecimento de informações para a tomada de decisão da inteligência competitiva das organizações. Reportagens de grandes meios de comunicação, em especial o "Globo Repórter (2019)", já publicaram matérias em artigos de suas páginas digitais sobre o bibliotecário, onde se referem ao mesmo como "o profissional do futuro" $(\mathrm{G} 1,2019)$.

Essa pesquisa responde positivamente à pergunta que a gerou: não só há espaço para o fazer biblioteconômico para além dos centros de informação tradicional, como dezenas de discentes de Biblioteconomia foram contratados pela empresa ao final ou durante seus estágios. Levando em conta o atual percentual de desemprego e crise econômica no Brasil, esses formandos encontraram através da Biblioteconomia, uma colocação profissional no mercado formal de emprego.

Muda-se o suporte, mas a gestão da informação ou a ciência da biblioteca como também é entendida a Biblioteconomia pela literatura, segue sua tradição e vocação atemporal. Enquanto evoluímos como sociedade da informação, o lugar do bibliotecário estará sempre reservado.

A Biblioteconomia continua a ser entendida pela maior parte do senso comum como uma profissão restrita a centros de pesquisas tradicionais. Esse entendimento acaba influenciando a consciência de uma pequena parte dos egressos que por vezes não enxergam na atuação biblioteconômica na atuação 
dos serviços de E-commerce praticados na empresa (objeto dessa pesquisa), mesmo tendo iniciado a carreira através do curso e crescido dentro da companhia. Por outro lado, uma parcela significativa dos profissionais da empresa (85\%) contemplados na pesquisa, não só enxergam como também creditam ao curso a competência para a sua atuação no E-commerce e a abertura de portas no mercado de trabalho.

O aumento do número de bacharéis em Biblioteconomia no E-commerce contribui para a visibilidade do bibliotecário como profissional da informação que pode atuar em diferentes organizações informacionais, tradicionais ou não, conforme a classificação da CBO e o CRB7.

$O$ avanço da Internet e consequentemente das transações comerciais feitas pelo canal contribuiu para uma maior exigência da gestão da informação e do conhecimento em empresas de comércio eletrônico, e abriu portas para o bibliotecário profissional da informação. Na empresa em que esta pesquisa foi aplicada, os 20 profissionais participantes do estudo de caso distribuídos nos seis setores, foram contratados pela companhia em função da formação biblioteconômica ao final, ou no curso ou durante os seus estágios.

Sugerimos que as universidades e seus respectivos cursos de Biblioteconomia percebam a necessidade de atualização de suas matrizes curriculares para o atendimento das demandas por profissionais da informação, em outras áreas que não apenas a biblioteca tradicional, preparando seus egressos de forma que os mesmos estejam cada vez mais preparados para o mercado digital.

Essa pesquisa demonstrou que as competências biblioteconômicas são postas em práticas no dia-a-dia do trabalho digital, seja através da classificação, da normalização, da filtragem de informações, da gestão de pessoas etc.

A pergunta de pesquisa que originou essa pesquisa foi respondida positivamente. Há espaço para a atuação profissional fora dos mercados tradicionais da informação. Essa pesquisa contribui para a Biblioteconomia ao evidenciar os egressos que atuam no mercado informacional de tendências que colocam em prática a competência biblioteconômica e mostra que o discente possui escolha ao decidir em sua graduação, seu eixo focal no mercado de 
trabalho: tradicional (bibliotecas, jornais, revistas), especializado (centros de pesquisa) ou no mercado informacional de tendências (sites, comércio eletrônico, consultoria).

\section{REFERÊNCIAS}

AMARAL, Roniberto Morato; GARCIA, Leonardo Guimarães; FARIA, Leandro Innocentini Lopes de; ALIPRANDINI, Dario Henrique. Modelo para o mapeamento de competências em equipes de inteligência competitiva. Ciência da Informação, Brasília, v. 37, n. 2, p. 7-19, ago. 2008. Disponível em: http://www.scielo.br/scielo.php?script=sci_arttext\&pid=S0100$19652008000200001 \&$ Ing=en\&nrm=iso. Acesso em: 25 maio 2019.

ASSOCIAÇÃO BRASILEIRA DE COMÉRCIO ELETRÔNICO. Notícias. Ecommerce brasileiro espera faturar $\mathbf{R} \$ \mathbf{5 9 , 9}$ bilhões em 2017. 2016.

Disponível em: https://abcomm.org/noticias/e-commerce-brasileiro-esperafaturar-r-599-bilhoes-em-2017/. Acesso em: 26 maio 2019.

BORGES, Maria Alice Guimarães. O profissional da informação: somatório de formações, competências e habilidades. In: BAPTISTA, Sofia Galvão; MUELLER, Suzana P. M. (Orgs.). Profissional da informação: espaço de trabalho. Brasília: Thesaurus, 2004. p. 55-69. Disponível em:

http://repositorio.unb.br/handle/10482/1447. Acesso em: 10 nov. 2018.

CAIRES, Beatriz Matos. Time integralização. [mensagem pessoal] Mensagem recebida por: allandavidns@gmail.com. Em: 24 jun. 2019.

CARVALHO SILVA, Jonathas Luiz. Normatividade, tecnicidade e/ou cientificidade da Biblioteconomia. Transinformação, Campinas, v. 25, n. 1, p. 5-17, abr. 2013. Disponível em:

http://www.scielo.br/scielo.php?script=sci_arttext\&pid=S0103-

$37862013000100001 \&$ Ing=en\&nrm=iso. Acesso em: 21 jun. 2019.

CLASSIFICAÇÃO BRASILEIRA DE OCUPAÇÕES. CBO. № 2612. Disponível em:

http://www.mtecbo.gov.br/cbosite/pages/pesquisas/ResultadoFamiliaAtividades. jsf. Acesso em: 20 jun. 2019.

CHAIM, Ricardo Matos. Comércio eletrônico ou canal de vendas eletrônico? Perspectivas em Ciência da Informação, Belo Horizonte, v. 5, n. 1, nov. 2007. ISSN 19815344. Disponível em: http://portaldeperiodicos.eci.ufmg.br/index.php/pci/article/view/548/310. Acesso em: 22 maio 2019.

CONSELHO REGIONAL DE BIBLIOTECONOMIA - 7ạ. Região. 0

profissional. Disponível em: http://www.crb7.org.br/carreira/o-profissional/. 
Acesso em: 10 nov. 2018.

CUNHA, Júlia Neves Ferreira. Treinamento de seo. Rio de Janeiro, 2019. 77 slides, color, $25 \mathrm{~cm} \times 20 \mathrm{~cm}$. In: TechWeek: Treinamento SEO. Treinamento Disponível em:

https://drive.google.com/file/d/14k6LA6zOXXvNQdySQvPqLeZc2pyovW3e/view Acesso em: 24 jun. 2019.

CUNHA, Murilo Bastos da; CAVALCANTI, Cordélia Robalinho de Oliveira. Dicionário de Biblioteconomia e Arquivologia. Brasília: Briquet de Lemos, 2008. xvi, $451 \mathrm{p}$.

DRUBSCKY, Luiza. O que é Inteligência de Conteúdo? Oriente seu conteúdo de forma inteligente com dados! 2018. Disponível em: https://rockcontent.com/blog/inteligencia-de-conteudo/. Acesso em: 10 nov. 2018.

FERREIRA, Carlos Alberto. Biblioteconomia digital: planos de aulas, 2018.1.

FONSECA, Edson Nery da. Introdução à Biblioteconomia. 2. ed. Brasília: Briquet de Lemos Livros, 2010. 152 p. ISBN: 85-85637-32-3.

GUNTHER, Hartmut. Pesquisa qualitativa versus pesquisa quantitativa: esta é a questão? Psicologia: teoria e pesquisa, Brasília, v. 22, n. 2, p. 201-209, ago. 2006. Disponível em:

http://www.scielo.br/scielo.php?script=sci_arttext\&pid=S0102-

$37722006000200010 \&$ Ing=en\&nrm=iso. Acesso em: 04 jul. 2019. http://dx.doi.org/10.1590/S0102-37722006000200010.

G1. Site. Globo repórter. Globo repórter revela quais características o profissional do futuro deve ter. 27 jun. 2019. Disponível em:

https://g1.globo.com/globo-reporter/noticia/2019/06/27/globo-reporter-revelaquais-caracteristicas-o-profissional-do-futuro-deve-ter.ghtml. Acesso em: 8 de jul. 2019.

IBGE. AGÊNCIA IBGE NOTÍCIAS/Sala de Imprensa. PAC 2014: receita das vendas pela internet cresceu 290,4\% desde 2007. [s./I.], 2016a. Disponível em: https://agenciadenoticias.ibge.gov.br/agencia-sala-de-imprensa/2013-agenciade-noticias/releases/9502-pac-2014-receita-das-vendas-pela-internet-cresceu290-4-desde-2007. Acesso em: 11 nov. 2018.

IBGE. AGÊNCIA IBGE NOTÍCIAS/Sala de Imprensa. IBGE: celular se consolida como o principal meio de acesso à internet no Brasil. 2016b. Disponível em: http://agenciabrasil.ebc.com.br/geral/noticia/2016-12/ibgecelular-se-consolida-como-o-principal-meio-de-acesso-internet-no-brasil. Acesso em: 07 jul. 2019.

IBGE. AGÊNCIA IBGE NOTÍCIAS/Sala de Imprensa. PNAD Contínua TIC 
2017: internet chega a três em cada quatro domicílios do país. 2018. Disponível em: https://agenciadenoticias.ibge.gov.br/agencia-sala-de-imprensa/2013agencia-de-noticias/releases/23445-pnad-continua-tic-2017-internet-chega-atres-em-cada-quatro-domicilios-do-pais. Acesso em: 26 maio 2019.

LINKEDIN. Site. About. 2019. Disponível em: https://about.linkedin.com/ptbr?trk=homepage-basic_directory. Acesso em: 25 jun. 2019.

LUCAS, Alexandre; CAFE, Ligia Maria Arruda; VIERA, Angel Freddy Godoy. Inteligência de negócios e inteligência competitiva na ciência da informação brasileira: contribuições para uma análise terminológica. Perspectivas em Ciência da Informação, Belo Horizonte, v. 21, n. 2, p. 168-187, jun. 2016. Disponível em: http://www.scielo.br/scielo.php?pid=S141399362016000200168\&script=sci_abstract\&tIng=pt. Acesso em: 20 jun. 2019.

MADUREIRA, Helania Oliveira; VILARINHO, Lúcia Regina Goulart. A formação do bibliotecário para atuar em bibliotecas digitais: uma questão a aprofundar. Perspectivas em Ciência da Informação, Belo Horizonte, v. 15, n. 3, p. 87106, set./dez. 2010. Disponível em: http://www.scielo.br/pdf/pci/v15n3/06.pdf. Acesso em: 10 nov. 2018.

MELMAN, Lucas. E-commerce Brasil. Glossário do marketplace: principais termos para entender esse mercado. 05 ago. 2016. Disponível em: https://www.ecommercebrasil.com.br/artigos/glossario-do-marketplaceprincipais-termos-para-entender-esse-mercado/. Acesso em: 04 jul. 2019.

MIRANDA, S. V. Identificando competências informacionais. Ciência da Informação, Brasília-DF, v. 33, n. 2, 2004. Disponível em: http://www.brapci.inf.br/_repositorio/2010/02/pdf_9422f0c8f8_0008165.pdf. Acesso em: 27 jul. 2019.

PONTES, Flavio Vieira; LIMA, Gercina Ângela Borém de Oliveira. A organização do conhecimento em ambientes digitais: aplicação da teoria da classificação facetada. Perspectivas em Ciência da Informação, Belo Horizonte, v. 17, n. 4, p. 18-40, dez. 2012. Disponível em: http://www.scielo.br/scielo.php?script=sci_arttext\&pid=S141399362012000400003\&lng=en\&nrm=iso. Acesso em: 21 jun. 2019. http://dx.doi.org/10.1590/S1413-99362012000400003.

REBELO, Tainara. Você acha o bibliotecário ultrapassado? saiba que a profissão está em alta. UOL, 2019. Disponível em: https://noticias.uol.com.br/tecnologia/noticias/redacao/2019/05/16/shlerlockholmes-da-web-biblioteconomista-virou-profissional-disputado.htm. Acesso em: 26 maio 2019.

SANTOS, Priscila Reis dos; MESQUITA, José Marcos Carvalho de; NEVES, Jorge Tadeu de Ramos; BASTOS, Alessandra Mesquita. Inserção no mercado de trabalho e a empregabilidade de bacharéis em Biblioteconomia. 
Perspectivas em Ciência da Informação, Belo Horizonte, v. 21, n. 2, p. 14-32, jun. 2016. Disponível em:

http://www.scielo.br/scielo.php?script=sci_arttext\&pid=S1413-

99362016000200014\&Ing=en\&nrm=iso. Acesso em: 21 jun. 2019.

http://dx.doi.org/10.1590/1981-5344/2563.

SEBRAE. Portal SEBRAE/Artigos. Integre seus canais de vendas a partir do conceito de omnichannel. Disponível em:

http://www.sebrae.com.br/sites/PortalSebrae/artigos/integre-seus-canais-devendas-a-partir-do-conceito-de-omnichannel,87426f65a8f3a410VgnVCM2000003c74010aRCRD. Acesso em: 26 maio 2019.

SILVEIRA, Denise Tolfo; CÓRDOVA, Fernanda Peixoto. A pesquisa científica. In: GERHARDT, Tatiana Engel; SILVEIRA, Denise Tolfo (Org.). Métodos de pesquisa. coordenado pela Universidade Aberta do Brasil - UAB/UFRGS e pelo Curso de Graduação Tecnológica - Planejamento e Gestão para o Desenvolvimento Rural da SEAD/UFRGS. - Porto Alegre: Editora da UFRGS, 2009. 120 p. : il. ; 17,5x25cm (Série Educação a Distância) Inclui figuras, quadros e anexos. Inclui referências. Disponível em:

https://www.unifesp.br/reitoria/dci/images/DCl/revistas/Entreteses/guia_referenc ias_ABNT_2014.pdf. Acesso em: 28 jul. 2019.

STATCOUNTER. Portal. Disponível em: https://statcounter.com/. Acesso em: 24 jun. 2019.

TEIXEIRA, Fabrício. Introdução e boas práticas em ux design. São Paulo: Casa do Código, 2015. 271 p. Disponível em:

https://pt.slideshare.net/info_cimol/introducao-e-boas-praticas-em-ux-design. Acesso em: 04 jul. 2019.

TOLEDO, Fernando. E-commerce Brasil. O que é sortimento? e para que serve? 2015. Disponível em: https://www.ecommercebrasil.com.br/artigos/oque-e-sortimento-e-para-que-serve/. Acesso em: 25 jun. 2019.

UNIVERSIDADE FEDERAL DO ESTADO DO RIO DE JANEIRO. UNIRIO. Escola de Biblioteconomia. Projeto político pedagógico do curso de bacharelado em Biblioteconomia. Comissão: Marcos Luiz Cavalcanti de Miranda et al. Rio de Janeiro: [s. n.], 2010. Disponível em: http://www.unirio.br/unirio/cchs/eb/graducao/bacharelado-noturno-1. Acesso em: 26 maio 2019.

VALENTIM, Marta Ligia Pomim. O moderno profissional da informação: formação e perspectiva profissional. Encontros Bibli: revista eletrônica de biblioteconomia e ciência da informação, Florianópolis, v. 5, n. 9, p. 16-28, jan. 2000. ISSN 1518-2924. Disponível em:

https://periodicos.ufsc.br/index.php/eb/article/view/12. Acesso em: 04 jul. 2019. doi: https://doi.org/10.5007/1518-2924.2000v5n9p16. 
VALENTIM, Marta Lígia Pomim. O profissional da informação: formação, perfil e atuação profissional. São Paulo: Polis, 2002. 156 p.

\title{
PERFORMANCE OF LIBRARIANSHIP IN E-COMMERCE
}

\begin{abstract}
Introduction: It exposes the growth and popularization of the Internet and E-commerce in Brazil and consequently the opening of new vacancies and jobs for information professionals. Objective: It aims to analyze library practice and the participation of librarians in an E-commerce company. Methodology: It presents a case study of an Ecommerce company and it discusses the responses to the application of a survey Results: It states that the librarian's role in E-commerce contributes to the visibility of the profession and that there is a place for library practice in non-traditional information markets as well as their placement in the formal job market. Conclusions: It concludes that the librarian has the skills to work in E-commerce. It suggests updating the curricular matrices to meet the library's economic demands in digital electronic commerce.
\end{abstract}

Descriptors: Librarianship. Librarian. E-commerce. Professional performance

\section{DESEMPEÑO DE LA BIBLIOTECOLOGÍA EN EL COMERCIO ELECTRÓNICO}

\begin{abstract}
RESUMEN
Introducción: Expone el crecimiento y la popularización de Internet y el comercio electrónico en Brasil y, en consecuencia, la apertura de nuevas vacantes y empleos para profesionales de la información. Objetivo: Analiza la práctica de la Bibliotecología y la participación de bibliotecarios en una empresa de comercio electrónico. Metodología: Presenta un estudio de caso de una empresa de comercio electrónico y analiza las respuestas a la aplicación de un cuestionario. Resultados: Declara que el papel del bibliotecario en el comercio electrónico contribuye a la visibilidad de la profesión y que hay un lugar para la práctica de la bibliotecología en los mercados de información no tradicionales, así como su colocación en el mercado laboral formal. Conclusiones: Concluye que el bibliotecario tiene las habilidades para trabajar en el comercio electrónico. Sugiere actualizar las matrices curriculares para satisfacer las demandas bibliotecarias y económicas en el comercio electrónico digital.
\end{abstract}

Descriptores: Bibliotecologĺa. Bibliotecario. Comercio electrónico. Actuación professional.

Recebido em: 24.01.2020

Aceito em: 07.05.2020 